\title{
Thunbergia laurifolia extract minimizes the adverse effects of toxicants by regulating P-glycoprotein activity, CYP450, and lipid metabolism gene expression in HepG2 cells
}

\author{
A. Rocejanasaroj ${ }^{1}$, T. Tencomnao ${ }^{2}$ and W. Sangkitikomol ${ }^{2}$ \\ 'Program in Clinical Biochemistry and Molecular Medicine, \\ Department of Clinical Chemistry, Faculty of Allied Health Sciences, \\ Chulalongkorn University, Bangkok, Thailand \\ ${ }^{2}$ Center for Excellence in Omics-Nano Medical Technology Development Project, \\ Department of Clinical Chemistry, Faculty of Allied Health Sciences, \\ Chulalongkorn University, Bangkok, Thailand \\ Corresponding author: W. Sangkitikomol \\ E-mail: warin.s@chula.ac.th
}

Genet. Mol. Res. 13 (1): 205-219 (2014)

Received March 10, 2013

Accepted December 3, 2013

Published January 10, 2014

DOI http://dx.doi.org/10.4238/2014.January.10.12

\begin{abstract}
Thunbergia laurifolia (TL) is widely used as an antidote in Thai traditional medicine against toxic substances such as alcohol, pesticides, arsenic, and strychnine. We found that the lyophilized form of TL in $80 \%$ ethanol possessed the antioxidant levels within the range $23,163.9 \pm 1457.4$ Trolox equivalents $\mathrm{mM} / \mathrm{kg}$ dry mass and $899.8 \pm$ 14.5 gallic acid equivalents $\mathrm{mM} / \mathrm{kg}$ dry mass using the oxygen radical absorbance capacity assay and the Folin Ciocalteu phenol assay, respectively. TL extract (TLE) at a high dose $(3000 \mathrm{mg} / \mathrm{L})$ induced cytotoxicity according to the neutral red assay and the MTT assay. However, TLE doses of 800-3000 mg/L could reduce intracellular oxidative stress in a dose-dependent manner $(\mathrm{P}<0.05)$ using the dichlorodihydrofluorescein diacetate assay. TLE significantly enhanced
\end{abstract}


the mRNA expression of CYP1A1, CYP1A2, CYP2B6, CYP3A4, and PPAR $\gamma$, but it significantly inhibited the mRNA expression of CYP3A7, CYP2D6, and CYP2E1 $(\mathrm{P}<0.05)$ by reverse transcription-polymerase chain reaction. Moreover, TLE could increase the activity of a multidrug transporter, P-glycoprotein, which accelerated the excretion of toxic substances from HepG2 cells. It is suggested that TLE may be beneficial for detoxification by reducing oxidative stress, minimizing toxicity by regulating the expression CYP450 mRNAs for suitable production of CYP450 isoenzymes, and increasing PPAR $\gamma$ mRNA expression and P-glycoprotein activity in HepG2 cells, thereby maintaining xenobiotic biotransformation balance.

Key words: Thunbergia laurifolia; Antioxidant; CYP450; P-glycoprotein

\section{INTRODUCTION}

Rang-jued is popularly consumed as herbal tea for the detoxification of toxic agents. Thunbergia laurifolia is called Rang-jued and Babbler's Bill in Thai and English, respectively. Actually, it is widely used in Thai traditional medicine for protection against food and environmental toxic agents. The extract of dried leaves, dried roots, fresh leaves, and bark of $T$. laurifolia can be effectively used as an antidote. The antidotal activity of T. laurifolia was used against pesticides, arsenic and strychnine poisonings (Tejasen and Thongthapp, 1980), and ethanol-induced hepatotoxicity (Pramyothin et al., 2005); its anti-inflammatory use (Wonkchalee et al., 2012) has also been reported. A variety of drugs and toxic chemicals are capable of generating free radicals in the body, which may cause many diseases such as cancer, cardiovascular disease, stroke, and aging. This plant is rich in antioxidants, which are capable of terminating free radical reactions and preventing oxidative damage. Different phytochemicals in herbal products are safer than synthetic medicine and beneficial in treatment of diseases caused by free radicals (Sen et al., 2010). Hepa $1 \mathrm{C1C7}$ cells that were treated with T. laurifolia extract could induce the phase II xenobiotic detoxification enzyme quinone reductase in a dose-dependent manner (Oonsivilai et al., 2007). Cytochrome P450 isoenzymes (CYP450) are involved in the metabolism of various endogenous chemicals such as fatty acids, steroids, hormones, bile acids, and eicosanoids and exogenous chemicals such as carcinogens, mutagens, xenobiotics, and environmental pollutants. These compounds have different structures that can be metabolized by CYP450. A major function of CYP450-catalyzed reactions is to convert these compounds into polar metabolites; they are conjugated by phase II enzymes and are thus easily excreted. The oxygen activation by the catalytic activity of CYP450 can result in the production of reactive oxygen species (ROS). Small amounts of the superoxide anion radicals $\left(\mathrm{O}_{2} \cdot-\right)$ can be synthesized from decay of the oxygenated CYP450 complex. Hydrogen peroxide $\left(\mathrm{H}_{2} \mathrm{O}_{2}\right)$ can form from dismutation of $\mathrm{O}_{2} \bullet$ - and decay of the peroxy-CYP450 complex. High amounts of ROS can lead to toxicity. However, a low concentration of ROS, especially $\mathrm{H}_{2} \mathrm{O}_{2}$, is important in signal transduction mechanisms in the cells and may be involved in cellular physiology and metabolism. CYP450 are involved in about $75 \%$ of the total drug metabolism, and most of them undergo deactivation by facilitated excretion from the body. 
However, many compounds are activated by CYP450 to form their active metabolites (Lander, 1997; Guengerich, 2008). Many toxic chemicals, drugs, and phytochemicals may increase or decrease the activities of various CYP450 either by enzyme induction or by inhibition. For example, Saint John's wort, an herbal remedy, induces CYP3A4 but inhibits CYP1A2 and CYP2D6 (Wenk et al., 2004). From a toxicological point of view, the adverse drug interactions with agents such as bioactive compounds that are found in grapefruit juice and some other fruit juices have been found to inhibit the CYP3A4 metabolism of cardiovascular drugs, leading to an overdose of these drugs (Bailey and Dresser, 2004).

The regulation of lipid homeostasis is associated with low-density lipoprotein receptor (LDLR), a membrane receptor, which contributes to lower plasma cholesterol levels by removing LDL from the blood circulation. The activity of 3-hydroxy-3-methylglutaryl-CoA reductase (HMG-CoAR), the rate-controlling enzyme, is expressed to synthesize cholesterol for cholesterol homeostasis in the cells (Powell and Kroon, 1994). The peroxisome proliferator-activated receptors [PPAR $(\alpha 1, \gamma)]$ and the liver X receptor $\alpha(\operatorname{LXR} \alpha)$, nuclear membrane receptors, are important regulators of cholesterol, fatty acid, and adipocyte differentiation. Many reports showed that the PPAR and LXR pathways regulate lipid homeostasis, antiinflammation, and metabolic syndrome via both the induction and repression of these target genes (Willson et al., 2001; Calkin and Tontonoz, 2010). These nuclear receptors are transcription factors that modulate gene expression that is relevant to the control of blood glucose and lipid homeostasis, as well as diabetes, chronic systemic inflammatory diseases, and carcinogenesis (Kaul et al., 2005).

P-glycoprotein (P-gp; ABCB1/MDR1), also known as ATP-binding cassette subfamily $\mathrm{B} 1$ (ABCB1) and multidrug resistance protein 1 (MDR1) in human cells, mediates the efflux drugs and many toxic agents from cells, and it plays a major role in the multidrug resistance of cancer cells (Hamidovic et al., 2010). It functions as a transporter by excreting drugs, toxic agents, and xenobiotics from the cells. Several natural compounds, dietary phytochemicals, and herbal medicines have the ability to modulate P-gp function and cause effects such as drug-drug, herb-drug, and herb-toxicant interactions. Co-medication with Saint John's wort gave results with a decreased concentration of drugs such as amitriptyline, cyclosporine, digoxin, indinavir, irinotecan, warfarin, phenprocoumon, alprazolam, dextrometorphan, simvastatin, and oral contraceptives, suggesting that Saint John's wort was a potent inducer of CYP3A4 and P-gp (Madabushi et al., 2006).

Although there are few reports of pharmacokinetic interactions between herbal medicines and toxic agents, these interactions naturally occur in humans. The role of herbal medicine, which can induce or repress CYP450 and modulate P-gp function to reduce the adverse effects of toxic agents through absorption, biotransformation, and excretion, is interesting. However, there is no report about the role of T. laurifolia in the gene expression of CYP450 isoenzymes, P-gp activity, and regulation of lipid metabolism gene expression. We were interested in studying the influence of T. laurifolia on CYP450-mediated metabolism in vitro to predict the possibility of reduced adverse effects from toxic substances. This investigation was performed to examine the ability of T. laurifolia extract to modulate the gene expression of major CYP450 in biotransformation, such as CYP1A1, CYP1A2, CYP3A4, CYP3A7, CYP2B6, CYP2C9, CYP2D6, and CYP2E1, and expression of lipid metabolism genes, such as LDLR, HMG-CoAR, PPAR $(\alpha 1, \gamma)$, and LXR $\alpha$ in HepG2 cells using reverse transcriptionpolymerase chain reaction (RT-PCR). Moreover, we determined the effect of T. laurifolia on the P-gp excretion ability using the rhodamine 123 uptake assay. 


\section{MATERIAL AND METHODS}

\section{Chemicals}

Folin Ciocalteu phenol (FCP) reagent, neutral red dye, ethidium bromide, 3-(4,5-dimethylthiazol-2-yl)-2,5-diphenyltetrazolium bromide (MTT), and 2',7'-dichlorofluorescein diacetate (DCFH-DA) were purchased from Sigma-Aldrich, St. Louis, MO, USA. Dulbecco's modified Eagle's medium (DMEM, with $4 \mathrm{mM}$ glutamine, $4500 \mathrm{mg} / \mathrm{L}$ glucose without sodium pyruvate), fetal bovine serum (FBS) and $1 \mathrm{X} 0.25 \%$ ethylenediaminetetraacetic acid (EDTA)-trypsin were obtained from Thermo Scientific HyClone, Logan, UT, USA. TRI Reagent was purchased from Molecular Research Center Inc., Cincinnati, OH, USA. RNase inhibitor, 100-bp DNA ladder, deoxyribonuclease I, and primers were purchased from Bio Basic Inc., Ontario, Canada. M-MuLV reverse transcriptase was purchased from Finnzymes Inc., Espoo, Finland. Amphotericin B (Fungizone) and penicillin-streptomycin solutions came from Biochrom AG, Berlin, Germany. All other basic reagents were of analytical grade.

\section{Preparation of HepG2 cells and biological analysis}

The HepG2 cell line was a generous gift from Assoc. Prof. Dr. Parvapan Bhattarakosol, Faculty of Medicine, Chulalongkorn University, Bangkok, Thailand. HepG2 cells were grown in DMEM supplemented with $4 \mathrm{mM}$ glutamine, $4.5 \mathrm{~g} / \mathrm{L}$ glucose, $10 \%$ heat-inactivated FBS, $0.1 \%$ amphotericin $\mathrm{B}$ (Fungizone), and $1 \%$ penicillin-streptomycin, and they were maintained at $37^{\circ} \mathrm{C}$ in a humidified atmosphere with $5 \% \mathrm{CO}_{2}$. The culture medium was changed twice per week, and the cells were subcultured once per week. The cells were seeded at a density of $1 \mathrm{x}$ $10^{6}$ cells/well on 6-well plates with a final volume of $5 \mathrm{~mL} /$ well for RT-PCR and $1 \times 10^{4}$ cells/ well on 96-well plates with a final volume of $0.2 \mathrm{~mL} /$ well for the cell viability test using the neutral red (NR) assay, MTT assay, and oxidative stress (DCFH-DA assay).

\section{Preparation of T. laurifolia extract (TLE)}

The leaves of T. laurifolia were collected from an herbal garden in Bangkok. The voucher specimen was botanically identified and given herbarium number 013424 (BCU) by Department of Botany, Faculty of Sciences, Chulalongkorn University, Bangkok, Thailand. TLE was prepared with dried leaves. In brief, $10 \mathrm{~g}$ leaves was milled and extracted in $1.0 \mathrm{~L}$ $80 \%$ methanol in water. This mixture was shaken in an ultrasonic bath for $60 \mathrm{~min}$ at $40^{\circ} \mathrm{C}$, cooled, and stored in the dark at $4^{\circ} \mathrm{C}$ for 2 days, after which the sediment was removed by centrifugation at $3000 \mathrm{rpm}$ for $15 \mathrm{~min}$. The extract was concentrated using a vacuum rotary evaporator at $50^{\circ} \mathrm{C}$ and freeze-dried giving a yield of $\sim 2 \mathrm{~g}$ dried extract. This dried extract was kept in a deep freezer at $-80^{\circ} \mathrm{C}$ until used.

\section{Determination of antioxidant activity in TLE}

The oxygen radical absorbance capacity (ORAC) assay and the FCP assay are the standard methods to determine the antioxidant properties (Huang et al., 2005). 


\section{ORAC assay}

The ORAC assay was used to measure the oxidative degradation of the fluorescent molecules after being mixed with free radical generator, 2,2'-azobis(2-amidinopropane) dihydrochloride (AAPH). Antioxidants can protect the fluorescent molecules from oxidative degradation. This assay was performed with some modification (Davalos et al., 2004). Briefly, $153 \mathrm{mM}$ AAPH in $75 \mathrm{mM}$ phosphate buffer, $\mathrm{pH}$ 7.4, was made daily. A 40- $\mu$ M fluorescein stock solution was made in $75 \mathrm{mM}$ phosphate buffer and stored at $4^{\circ} \mathrm{C}$. Immediately prior to use, the stock solution was diluted 1:1000 with $75 \mathrm{mM}$ phosphate buffer. To a 96-well plate, including blank wells, all wells received $25 \mu \mathrm{L} 75 \mathrm{mM}$ phosphate buffer, standards received $25 \mu \mathrm{L}$ Trolox solution $(10,20,30,40,60$, and $80 \mathrm{mM}$ ), and samples received $25 \mu \mathrm{L}$ sample dilution and $150 \mu \mathrm{L}$ working sodium fluorescein solution, which was mixed for $5 \mathrm{~s}$. The plate was equilibrated by incubating it for a minimum of $30 \mathrm{~min}$ at $37^{\circ} \mathrm{C}$ in the Wallac 1420 VICTOR2 Multilabel Counter (Perkin Elmer Life and Analytical Sciences, Finland). The reaction was initiated by $25 \mu \mathrm{L}$ AAPH solution and followed by shaking for $10 \mathrm{~s}$. The fluorescence was then monitored kinetically with data taken every minute using $485 \mathrm{~nm}$ for excitation and $535 \mathrm{~nm}$ for emission. The plate reader 1420 VICTOR 2 was controlled by the Wallac 1420 Software Version 3.00. The fluorescence of each well was measured every minute for $35 \mathrm{~min}$. ORAC values were calculated by using area under curve (AUC). The AUC and the net AUC of the standards and samples were determined using the Wallac 1420 Software with the following equations: net AUC standard = AUC standard - AUC blank and net AUC sample $=$ AUC sample - AUC blank.

The loss in fluorescence can be assessed by measuring the AUC of the kinetic plot for each concentration. The greater the extent of florescent decay, the smaller the expected AUC value would be. When net AUC values were calculated from these kinetic curves and plotted against the Trolox concentration, a linear relationship was observed. The results are reported as Trolox equivalents (TE) $\mathrm{mM} / \mathrm{kg}$ dry mass.

\section{FCP assay}

A modified FCP assay (Singleton et al., 1999) was used to determine the reducing properties of the phenolic contents. Briefly, $500 \mu \mathrm{L}$ samples or standards was mixed with 500 $\mu \mathrm{L} 10 \%$ FCP reagent and allowed to stand for $20 \mathrm{~min}$. To this, $350 \mu \mathrm{L} 10 \mathrm{mM} \mathrm{Na}_{2} \mathrm{CO}_{3}$ was added and mixed and allowed to stand for $20 \mathrm{~min}$ for the solution to turn blue, and then the absorbance at $750 \mathrm{~nm}$ was measured using $1.562,3.125,6.25,12.5,25$, and $50 \mathrm{mg} / \mathrm{L}$ gallic acid as the standards. The results are reported as gallic acid equivalents (GE) $\mathrm{mM} / \mathrm{kg}$ dry mass. This method was carried out using a Shimadzu UV 1601 spectrophotometer.

\section{Cell survival assay using the NR assay}

HepG2 cell viability was assessed using the NR assay as previously described (Zhang et al., 1990), with some modifications. Briefly, following the cell treatments, HepG2 cells were exposed to $100 \mu \mathrm{L} 0.4 \% \mathrm{NR}$ solution in phosphate-buffered saline (PBS), $\mathrm{pH} 7.5$, for $3 \mathrm{~h}$ at $37^{\circ} \mathrm{C}$ to allow the lysosomes of viable cells to take up the vital stain (NR). This process requires metabolically active cells. Failure to take up NR indicated that those cells had suffered damage. 
The cultures were rapidly washed with $1 \%$ formaldehyde, $1 \%$ calcium chloride to remove the excess NR. A mixture of $1 \%$ acetic acid, $50 \%$ ethanol was added to the HepG2 cells to extract the NR from these cells at room temperature for $30 \mathrm{~min}$. The supernatants were transferred to a 96-well plate, and the absorbance at $550 \mathrm{~nm}$ was measured. This method was carried out using VICTOR2 Multilabel Counter (Perkin Elmer Life and Analytical Sciences, Finland). The percent cell survival was calculated according to the following formula: $\%$ cell survival $=[(a b-$ sorbance of treated group - blank) / (absorbance of control group - blank)] x 100.

\section{Cellular activity assay using the MTT assay}

HepG2 cell activity was assessed using the MTT assay as previously described (Twentyman and Luscombe, 1987), with some modifications. The assay is dependent on the ability of viable cells to metabolize MTT, a water-soluble tetrazolium salt (yellow color), by mitochondrial succinate dehydrogenase into a water-insoluble formazan product (dark purple color). Briefly, following the cell treatments, HepG2 cells in each well of the 96-well plate were subjected to the MTT assay by adding $20 \mu \mathrm{L} 0.5 \%$ MTT solution in PBS and incubating at $37^{\circ} \mathrm{C}$ in $5 \% \mathrm{CO}_{2}$ for $4 \mathrm{~h}$. Subsequently, the medium was removed, $150 \mu \mathrm{L} 50 \%$ ethanol in dimethyl sulfoxide was added to each well to dissolve the formazan product, and the absorbance was measured at $550 \mathrm{~nm}$. Because the reduction of MTT occurred in metabolically active cells, the level of activity was a measure of the viability of the cells. This method was carried out using VICTOR2 Multilabel Counter. The percent cellular activity was calculated according to the following formula: \% cellular activity $=[($ absorbance of treated group - blank $) /$ (absorbance of control group - blank)] x 100.

\section{DCFH-DA assay}

DCFH-DA is used as a substrate to measure oxidant production in the HepG2 cells (Wang and Joseph, 1999). Briefly, following the cell treatments, HepG2 cells were centrifuged for $10 \mathrm{~min}$ at $3000 \mathrm{rpm}$ and then washed 3 times with PBS, pH 7.4. The cells were mixed with $100 \mu \mathrm{L} 100 \mathrm{mM}$ DCFH-DA in PBS and incubated for $90 \mathrm{~min}$ at $37^{\circ} \mathrm{C}$ in a humidified $5 \% \mathrm{CO}_{2}$ atmosphere. The non-ionic, non-polar DCFH-DA crosses cell membranes and is hydrolyzed by intracellular esterases to non-fluorescent dichlorofluorescin (DCFH). In the presence of ROS inside the cells, DCFH is oxidized to highly fluorescent dichlorofluorescein (DCF). The cells were centrifuged for $10 \mathrm{~min}$ at $3000 \mathrm{rpm}$ and then washed 3 times with PBS, pH 7.4. The fluorescent measurement was monitored using VICTOR2 Multilabel Counter with excitation at $485 \mathrm{~nm}$ and emission at $535 \mathrm{~nm}$. Therefore, the intracellular DCF fluorescence can be used as an index to quantify the overall oxidative stress in the cells. The percent cellular oxidative stress was calculated according to the following formula: $\%$ cellular oxidative stress $=[($ fluorescence of treated group - blank) / (fluorescence of control group - blank)] x 100.

\section{Expression of CYP450 and lipid metabolism genes using RT-PCR}

In this investigation, gene expression was detected using the RT-PCR method according to previous reports, with minor modifications (Powell and Kroon, 1994; Kaul et al., 2005). Briefly, $1 \times 10^{6}$ HepG2 cells suspended in DMEM on 6-well plates were mixed with TLE (0- 
$600 \mathrm{mg} / \mathrm{L}, 0=$ control). After incubation for $29 \mathrm{~h}$ at $37^{\circ} \mathrm{C}$ in a humidified $5 \% \mathrm{CO}_{2}$ atmosphere, total RNA was isolated from HepG2 cells using the TRI reagent following the manufacturer protocol. The purity and quantity of total RNA were determined using agarose gel electrophoresis and a spectrophotometer. The synthesis of cDNA was performed using $2 \mu \mathrm{g}$ total RNA, random primers, and M-MuLV reverse transcriptase at $42^{\circ} \mathrm{C}$ for $1 \mathrm{~h}$. Subsequently, PCR was carried out using specific primer pairs in order to generate PCR products, which were 302-bp CYP1A1 (sense 5'-TTCGTCCCCTTCACCATC-3' and antisense 5'-CTGAATTCCACCCGT TGC-3'), 254-bp CYP1A2 (sense 5'-TCGTAAACCAGTGGCAGGT-3' and antisense 5'-GGT CAGGTCGACTTTCACG-3'), 283-bp CYP2B6 (sense 5'-ATGGGGCACTGAAAAAGACT GA-3' and antisense 5'-AGAGGCGGGGACACTGAATGAC-3'), 308-bp CYP2C9 (sense 5'-CTGGATGAAGGTGGCAATTT-3' and antisense 5'-AGATGGATAATGCCCCAGAG-3'), 341-bp CYP2D6 (sense 5'-AGCTGCTAACTGAGCACAGGATGA-3' and antisense 5'-AAAGCGCTGCACCTCATGAATCAC-3'), 297-bp CYP2E1 (sense 5'-GACTGTGGCCG ACCTGTT-3' and antisense 5'-ACTACGACTGTGCCCTTGG-3'), 314-bp CYP3A4 (sense 5'-ATTCAGCAAGAAGAACAAGGACA-3' and antisense 5'-TGGTGTTCTCAGGCACAG AT-3'), 306-bp CYP3A7 (sense 5'-GGTTCAGTAAAAAGAACAAGGACAA-3' and antisense 5'-TGGGGCACAGCTTTCTTAAA-3'), 258-bp LDLR (sense 5'-CAATGTCTCACCA AGCTCTG-3' and antisense 5'-TCTGTCTCGAGGGGTAGCTG-3'), 247-bp HMG-CoAR (sense 5'-CTTGTGTGTCCTTGGTATTAGAGCTT-3' and antisense 5'-TTATCATCTTGACC CTCTGAGTTACAG-3'), 728-bp PPAR $\alpha 1$ and 525-bp PPAR $\alpha 2$ (sense 5'-AGTCTCCCAGTGG AGCATTGAACA-3' and antisense 5'-ATACGCTACCAGCATCCCGTCTTT-3'), 434-bp PPAR $\gamma$ (sense 5'-AGCCTCATGAAGAGCCTTCCAACT-3' and antisense 5'-TGTCTTTCCT GTCAAGATCGCCCT-3'), 818-bp LXR $\alpha$ (sense 5'-AACCCACAGAGATCCGTCCACAAA-3' and antisense 5'-ATTCATGGCCCTGGAGAACTCGAA-3'), and 656-bp $\beta$-actin (sense 5'-ACGGGTCACCCACACTGTGC-3' and antisense 5'-CTAGAAGCATTTGCGGTGGACG ATG-3'). RT-PCR products along with a DNA ladder were electrophoresed on an agarose gel and visualized by ethidium bromide staining using a gel documentation system. For data analysis, the Gene Tools software 3.08 (SynGene, Cambridge, UK) was used. The expression of genes was normalized to that of $\beta$-actin, and data for treatment with each TLE concentration are reported as fold-change in normalized mRNA expression relative to that of control (no TLE treatment).

\section{P-gp activity or transport assay (rhodamine 123 efflux assay)}

The transport assay followed a previous study (Jia and Wasan, 2008), with minor modification. HepG2 cells $\left(5 \times 10^{4}\right)$ were cultured using a 96-well plate. The culture medium was removed and washed twice with ice-cold PBS after incubation for $29 \mathrm{~h}$. One hundred microliters $10 \mu \mathrm{M}$ rhodamine 123 in Hank's balanced salt solution was added to each well and incubated at $37^{\circ} \mathrm{C}$. After incubating for $1 \mathrm{~h}$, the supernatant was removed and washed twice with ice-cold PBS. Different concentrations of TLE, Verapamil (as a P-gp inhibitor), and PBS were added into correspondent wells and incubated at $37^{\circ} \mathrm{C}$ for $4 \mathrm{~h}$. The medium was removed, and the cells were washed twice with ice-cold PBS. Then, $100 \mu \mathrm{L} 0.1 \%$ Triton X-100 was added for cell lysis, and the fluorescence was measured with excitation at $485 \mathrm{~nm}$ and emission at $528 \mathrm{~nm}$. The relative intensity of the intracellular accumulation of rhodamine 123 was calculated relative to that of the control. 


\section{Statistical analysis}

All data are reported as means \pm SE for at least 3 independent experiments. Statistically significant differences between control and treated groups were evaluated by one-way analysis of variance (ANOVA) (SPSS version 11.0 for Windows) followed by the least significant differences (LSD) statistical test. The $\mathrm{P}$ value was two-tailed, and $\mathrm{P} \leq 0.05$ was considered to be statistically significant when comparing the data sets.

\section{RESULTS}

\section{Total antioxidant activity of TLE}

Antioxidants of TLE were measured by the ORAC and FCP assays (Table 1). The lyophilized TLE possessed antioxidant levels of 23,163.9 $\pm 1457.4 \mathrm{TE} \mathrm{mM} / \mathrm{kg}$ dry mass and $899.8 \pm 14.5 \mathrm{GE} \mathrm{mM} / \mathrm{kg}$ dry mass by the ORAC and FCP assays, respectively. Subsequently, lyophilized TLE was used to study the effect on cell viability, oxidative stress, P-gp activity, and expression of CYP450 and lipid metabolism genes.

Table 1. Total antioxidant activity of Thunbergia laurifolia extract by ORAC and FCP assays.

\begin{tabular}{lcc}
\hline T. laurifolia & ORAC assay (TE mM/kg dry mass) & FCP assay (GE mM/kg dry mass) \\
\hline Lyophilized extract & $23,163.9 \pm 1457.4$ & $899.8 \pm 14.5$
\end{tabular}

Data are reported as means \pm SE. All experiments were performed for at least three independent experiments. $\mathrm{TE}=$ Trolox equivalent; $\mathrm{GE}=$ gallic acid equivalent.

\section{Effects of TLE on cell survival and oxidative stress in HepG2 cells}

According to the HepG2 cell viability tests, $3000 \mathrm{mg} / \mathrm{L}$ TLE significantly reduced the number of living cells (NR assay; Figure 1A), and the same dose of TLE significantly decreased the activity of cellular metabolizing enzymes $(\mathrm{P}<0.05)$ (MTT assay; Figure 1B) upon incubation for $29 \mathrm{~h}$. In the DCFH-DA assay, HepG2 cells that were treated with $\geq 800 \mathrm{mg} / \mathrm{L}$ TLE had significantly reduced oxidative stress $(\mathrm{P}<0.05)$ that was dose-dependent (Figure 1C).

\section{Effects of TLE on the expression of CYP450 and lipid metabolism genes}

The mRNA expression of CYP450 genes was investigated in a xenobiotic biotransformation system (Figure 2 and Table 2). Doses of TLE from 200 to $600 \mathrm{mg} / \mathrm{L}$ enhanced the expression of the CYP1A1 gene, but the same doses inhibited the expression of the CYP2E1 gene. Doses of TLE from 400 to $600 \mathrm{mg} / \mathrm{L}$ enhanced the CYP2B6 gene, and $600 \mathrm{mg} / \mathrm{L} \mathrm{TLE}$ enhanced the expression of the CYP1A2 gene in HepG2 cells $(\mathrm{P}<0.05)$. The $200 \mathrm{mg} / \mathrm{L}$ TLE dose significantly increased CYP3A4 mRNA, whereas $600 \mathrm{mg} / \mathrm{L}$ TLE inhibited CYP3A4 mRNA $(\mathrm{P}<0.05)$. The $600 \mathrm{mg} / \mathrm{L}$ TLE dose inhibited the CYP2D6 and CYP3A7 genes. A difference in mRNA expression in response to various concentrations of TLE was not observed for the CYP2C9 gene. With regard to the mRNA expression of lipid metabolism genes, no differences were observed for LDLR, HMG-CoAR, PPAR $\alpha$, and LXR, but $400 \mathrm{mg} / \mathrm{L}$ TLE significantly enhanced PPAR $\gamma$ mRNA expression in HepG2 cells $(\mathrm{P}<0.05)$ (Figure 3 and Table 3 ). 
A

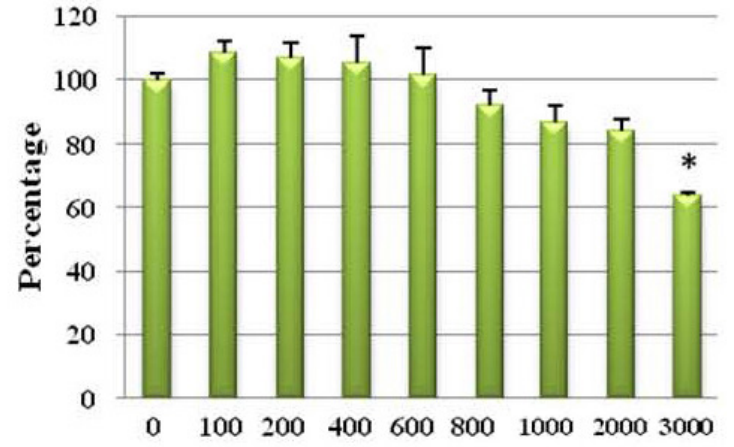

Concentration of TLE (mg/L)

B

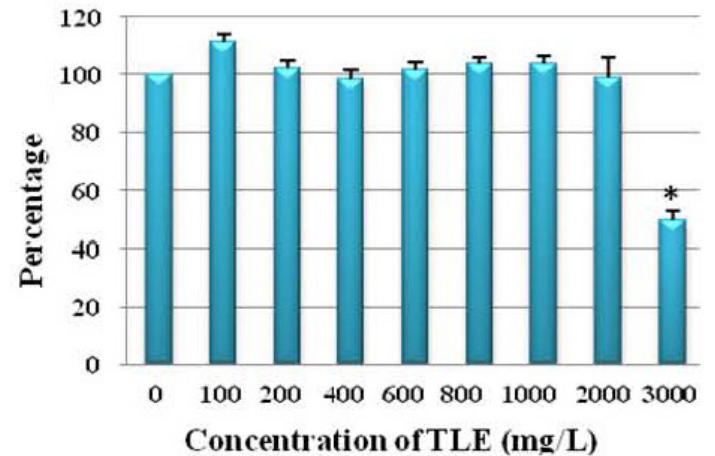

C

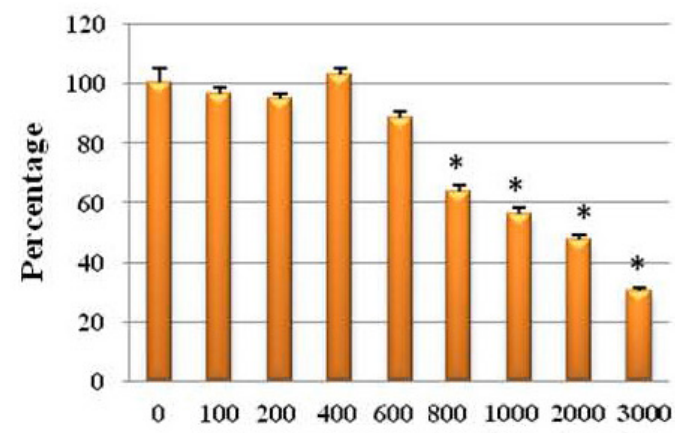

Concentration of TLE (mg/L)

Figure 1. Effects of Thunbergia laurifolia extract (TLE) on cell viability and oxidative stress of HepG2 cells. HepG2 cells were incubated with different concentrations of TLE $(0-3000 \mathrm{mg} / \mathrm{L}, 0=$ control $)$ at the end of experimental period of 29 h. A. The number of living HepG2 cells was determined using neutral red assay. B. The cellular activity of living HepG2 cells was assessed using the MTT assay. C. The oxidative stress in HepG2 cells was evaluated using the DCFH-DA assay. Values are reported as means with their SE shown by vertical bars. All experiments were performed for at least three independent experiments $(\mathrm{N}=3)$. ${ }^{*} \mathrm{P}<0.05$ for significant change as compared to control (no treatment). 

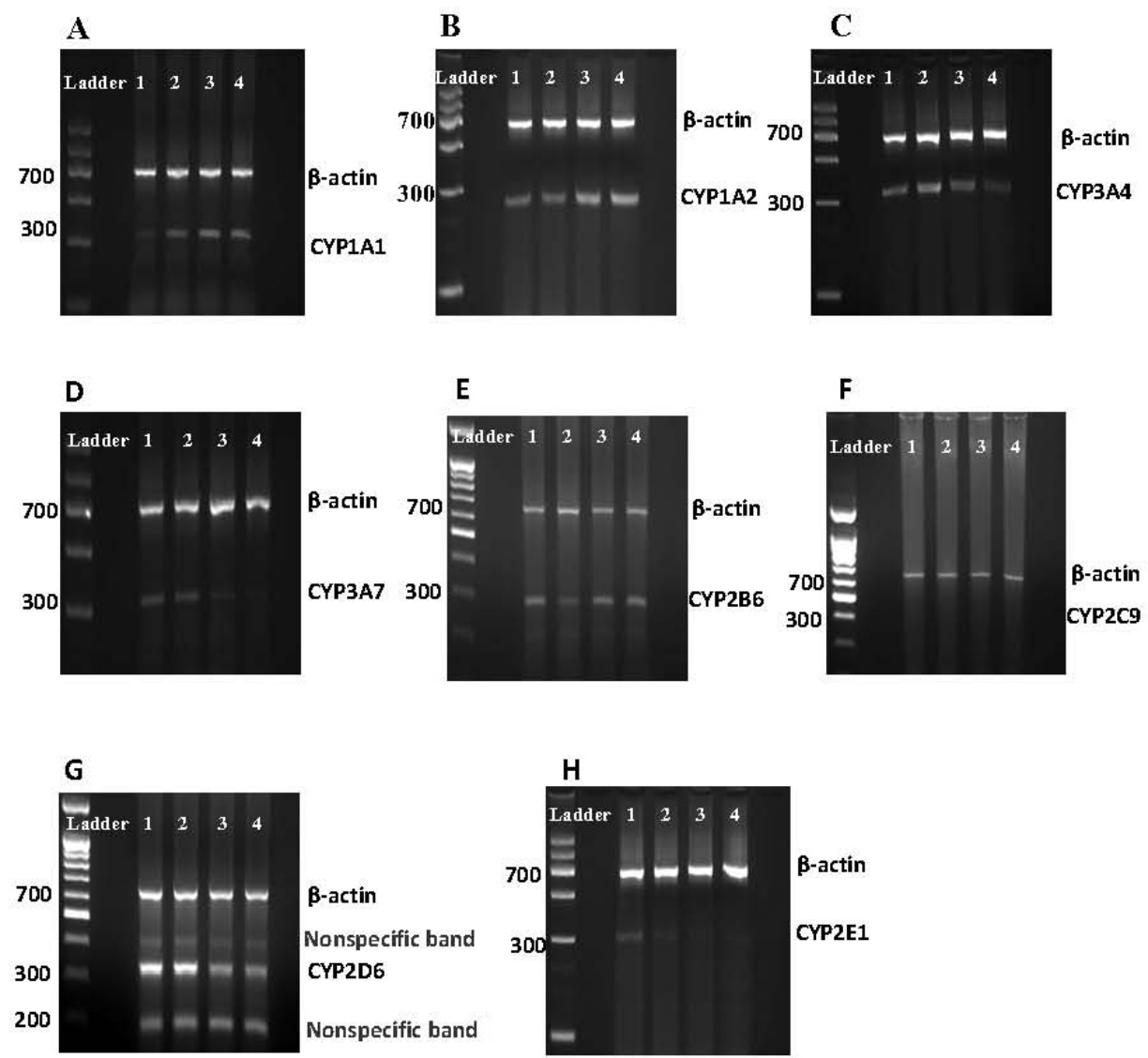

Figure 2. Effects of Thunbergia laurifolia extract (TLE) on mRNA expression of CYP450 (CYP1A1, CYP1A2, CYP3A4, CYP3A7, CYP2B6, CYP2C9, CYP2D6, and CYP2E1) in HepG2 cells treated with TLE (0 to 600 $\mathrm{mg} / \mathrm{L}$; lane $1=0$; lane $2=200$; lane $3=400$; lane $4=600$ ) and determined using the RT-PCR approach. Representative agarose gel photographs showed RT-PCR products corresponding to expected sizes of the CYP450 drug metabolism genes studied. mRNA expression of the $\beta$-actin gene was used for normalization. A. CYP1A1, B. CYP1A2, C. CYP3A4, D. CYP3A7, E. CYP2B6, F. CYP2C9, G. CYP2D6, and H. CYP2E1.

Table 2. Effects of Thunbergia laurifolia extract on CYP450 gene expressions in HepG2 cells.

\begin{tabular}{lllllllll}
\hline \multirow{2}{*}{ TLE $(\mathrm{mg} / \mathrm{L})$} & \multicolumn{7}{c}{ CYP450 mRNA expressions (relative levels) } \\
\cline { 2 - 8 } & \multicolumn{1}{c}{ CYP1A1 } & \multicolumn{1}{c}{ CYP1A2 } & \multicolumn{1}{c}{ CYP3A4 } & \multicolumn{1}{c}{ CYP3A7 } & \multicolumn{1}{c}{ CYP2B6 } & CYP2C9 & CYP2D6 & CYP2E1 \\
\hline 0 (control) & $0.999 \pm 0.049$ & $1.000 \pm 0.189$ & $1.000 \pm 0.079$ & $0.999 \pm 0.316$ & $1.000 \pm 0.089$ & Very low & $1.000 \pm 0.126$ & $1.000 \pm 0.055$ \\
200 & $1.446 \pm 0.050^{*}$ & $1.020 \pm 0.137$ & $2.106 \pm 0.231^{*}$ & $0.933 \pm 0.147$ & $0.919 \pm 0.137$ & Very low & $0.914 \pm 0.047$ & $0.698 \pm 0.059^{* *}$ \\
400 & $1.801 \pm 0.548^{*}$ & $1.286 \pm 0.378$ & $0.956 \pm .032$ & $0.716 \pm 0.148$ & $1.318 \pm 0.202^{*}$ & Very low & $0.890 \pm 0.009$ & $0.584 \pm 0.042^{* *}$ \\
600 & $1.705 \pm 0.227^{*}$ & $1.344 \pm 0.048^{*}$ & $0.572 \pm 0.023^{* *}$ & $0.579 \pm 0.043^{* *}$ & $1.296 \pm 0.037^{*}$ & Very low & $0.802 \pm 0.044^{* *}$ & $0.556 \pm 0.055^{* *}$ \\
\hline
\end{tabular}

Values derived from normalized band intensities are reported as means \pm SE from Figure 2. mRNA expression of CYP450 gene (CYP1A1, CYP1A2, CYP3A4, CYP3A7, CYP2B6, CYP2C9, CYP2D6, and CYP2E1) in HepG2 cells treated with varying concentrations of $T$. laurifolia extract (TLE, 0-600 mg/L;0 = control) were evaluated using RT-PCR. mRNA expression of the genes studied was normalized to that of the $\beta$-actin gene. All experiments were performed for at least three independent experiments $(\mathrm{N}=3) . *{ }^{*} * \mathrm{P}<0.05$ for significant change in normalized gene expressions as compared to control. 

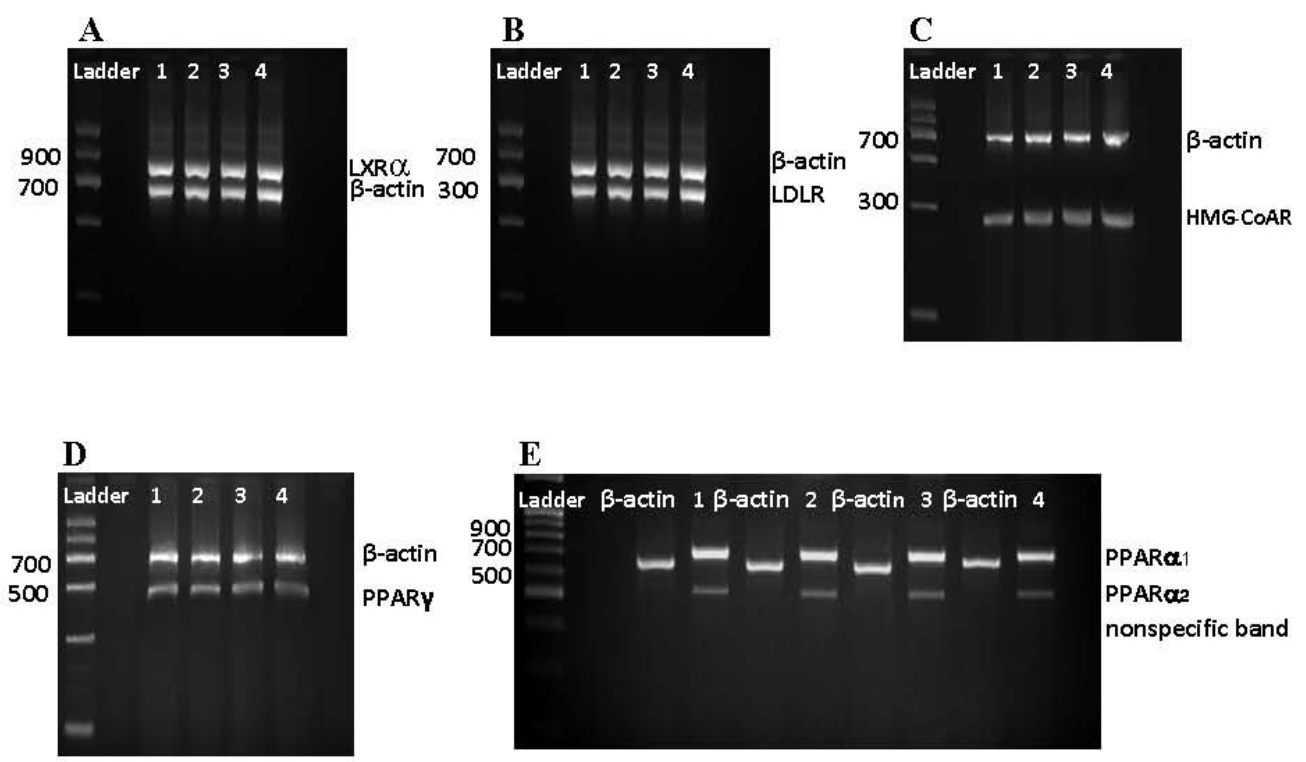

Figure 3. Effects of Thunbergia laurifolia extract (TLE) on mRNA expression of lipid metabolism genes in HepG2 cells determined using the RT-PCR method. Representative agarose gel photographs showed RT-PCR products corresponding to expected sizes of the lipid metabolism genes. A. LXR $\alpha$, B. LDLR, C. HMG-CoAR, D. PPAR $\gamma$, E. PPAR $\alpha 1$ and PPAR $\alpha 2$ nonspecific bands (isoform). mRNA expression of the $\beta$-actin gene was used for normalization. HepG2 cells were treated with TLE $(0$ to $600 \mathrm{mg} / \mathrm{L}$; lane $1=0$; lane $2=200$; lane $3=400$; lane $4=600$ ). $\mathrm{LXR} \alpha=$ liver X receptor $\alpha$; LDLR = low-density lipoprotein receptor; HMG-CoAR = 3-hydroxy-3methylglutaryl-CoA reductase; PPAR $=$ proliferator-activated receptors.

Table 3. Effects of Thunbergia laurifolia extract on lipid metabolism gene expressions in HepG2 cells.

\begin{tabular}{cccccc}
\hline TLE $(\mathrm{mg} / \mathrm{L})$ & \multicolumn{5}{c}{ Lipid metabolism mRNA expressions (relative levels) } \\
\cline { 2 - 6 } & PPAR $\alpha 1$ & PPAR $\gamma$ & LDLR & HMG-CoAR & LXR \\
\hline 0 & $1.000 \pm 0.050$ & $1.000 \pm 0.103$ & $1.000 \pm 0.251$ & $1.000 \pm 0.070$ & $1.000 \pm 0.049$ \\
200 & $0.996 \pm 0.045$ & $1.117 \pm 0.047$ & $1.082 \pm 0.198$ & $1.024 \pm 0.043$ & $1.028 \pm 0.067$ \\
400 & $1.042 \pm 0.041$ & $1.261 \pm 0.031^{*}$ & $1.056 \pm 0.195$ & $1.132 \pm 0.067$ & $1.063 \pm 0.007$ \\
600 & $0.986 \pm 0.024$ & $0.866 \pm 0.030$ & $1.013 \pm 0.089$ & $1.083 \pm 0.036$ & $1.064 \pm 0.015$ \\
\hline
\end{tabular}

Values derived from normalized band intensities are reported as means \pm SE from Figure 3. mRNA expression of lipid metabolism genes (PPAR $\alpha$ 1, PPAR $\gamma$, LDLR, HMG-CoAR, and LXR) in HepG2 cells treated with varying concentrations of T. laurifolia extract (TLE, $0-600 \mathrm{mg} / \mathrm{L} ; 0=$ control) evaluated using RT-PCR method. The mRNA expression of the genes studied was normalized to that of the $\beta$-actin gene. All experiments were performed for at least three independent experiments $(\mathrm{N}=3)$. ${ }^{*} \mathrm{P}<0.05$ for significant change in normalized gene expression as compared to control.

\section{Effects of TLE on P-gp activity}

The P-gp activity was determined using the rhodamine 123 efflux assay (Table 4). Doses of TLE from 200 to $2000 \mathrm{mg} / \mathrm{L}$ significantly increased P-gp activity in HepG2 cells from 15 to $37 \%(\mathrm{P}<0.05)$, and $50 \mu \mathrm{M}$ Verapamil could inhibit 50\% P-gp activity. The significant change of P-gp activity was detected by comparing expression after TLE treatment to that of control (no treatment) and using Verapamil as an inhibitor. 
Table 4. Effect of Thunbergia laurifolia on P-glycoprotein activity using the Rhodamine123 efflux assay.

\begin{tabular}{lc}
\hline TLE $(\mathrm{mg} / \mathrm{L})$ & \% P-glycoprotein activity \\
\hline 0 (control) & $100 \pm 3$ \\
100 & $109 \pm 2$ \\
200 & $115 \pm 2^{*}$ \\
400 & $121 \pm 3^{*}$ \\
600 & $124 \pm 3^{*}$ \\
800 & $135 \pm 2^{*}$ \\
1000 & $133 \pm 2^{*}$ \\
Verapamil $(50 \mu \mathrm{M})$ & $137 \pm 3^{*}$ \\
\hline
\end{tabular}

P-glycoprotein activity in HepG2 cells treated with varying concentrations of T. laurifolia extract (TLE, 0-2000 $\mathrm{mg} / \mathrm{L} ; 0=$ control) evaluated using the Rhodamine 123 efflux assay and Verapamil as an inhibitor. Values are reported as \pm means SE. All experiments were performed for at least three independent experiments $(\mathrm{N}=3)$. $*, * * \mathrm{P} \leq 0.05$ for significant change in P-glycoprotein activity as compared to control (no treatment).

\section{DISCUSSION}

The cellular activity and the number of living HepG2 cells were significantly reduced with the highest dose of TLE by the MTT assay and the NR assay, respectively. Oxidative stress-induced ROS production, detected by the DCFH-DA assay, was significantly decreased by TLE in a dose-dependent manner. Based on this particular experiment, we found that TLE reduced oxidative stress in HepG2 cells in a dose-dependent manner. Therefore, the toxic effect of TLE $(3000 \mathrm{mg} / \mathrm{L})$ on HepG2 cells may be because of its inhibitory or stimulatory actions via kinase signaling pathways, which are likely to affect cellular function by altering the phosphorylation state of target molecules and by modulating gene expression (Williams et al., 2004). These findings suggest that high concentrations of TLE may not be appropriate for health-promoting purposes. Other studies indicated that higher concentrations of flavonoids may sustain the activation of mitogen-activated protein kinases or stress-activated protein kinases, which could induce apoptosis; lower concentrations of flavonoids could lead to antioxidant response element-mediated gene expression, including that of phase II detoxifying enzymes (Chen et al., 2000; Kong et al., 2000).

We analyzed the effects of TLE on mRNA expression of CYP450 genes using RTPCR, and we found that TLE effectively downregulated the mRNA expression of CYP2E1. TLE is used in Thai traditional medicine to protect against food and environmental toxicants because TLE contained potential antioxidants and could induce P-gp activity. Moreover, the TLE-downregulated CYP2E1 expression may result in reduced CYP2E1 enzyme, which is involved in the metabolic activation of many toxic compounds such as ethanol (Butura et al., 2009), carbon tetrachloride (Takahashi et al., 2002), and acetaminophen (Kim et al., 2007). The ability of acute and chronic ethanol consumption to increase CYP2E1 activity is related to the production of ROS, and enhanced oxidation of lipids, proteins, and DNA have been reported (Butura et al., 2009). Diabetes induced the expression of CYP2E1 mRNA and protein levels several fold (Woodcroft et al., 2002). TLE was used to efficiently treat patients with ethanol-induced hepatotoxicity and diabetes mellitus; this may be because of its downregulation of CYP2E1 gene expression and antioxidant activity. Moreover, TLE could inhibit $\alpha$-amylase activity to reduce diabetes risk (Jaiboon et al., 2011). Arsenic is a well-known ROS inducer; its oxidative damage may lead to pathological conditions and play a role in adverse health ef- 
fects (Kumagai and Sumi, 2007). TLE is used to treat arsenic toxicity possibly because of its potential antioxidant activity and P-gp activation.

Organophosphorus pesticides are very toxic because they efficiently inhibit CYP1A1, CYP1A2, CYP2B6, and CYP3A4 activities (Abass et al., 2009). Strychnine, a highly toxic alkaloid, was mainly metabolized by CYP3A (Han et al., 2009). Most of the primary metabolites of the cannabinoids indicate CYP3A4 as a major enzyme that is involved in metabolic deactivation by human hepatic microsomes (Watanabe et al., 2007). Codeine is activated by CYP2D6 and leads to the production of morphine and morphine-6-glucuronide, which are pharmacologically more potent than codeine (Gasche et al., 2004). TLE significantly minimized the adverse effects of pesticides and strychnine by its induction of CYP1A1, CYP1A2, CYP2B6, and CYP3A4 mRNAs, and it may increase the enzyme production that is responsible for detoxification. TLE is used to treat drug addiction; this effect may be due to the induction of CYP3A4 mRNA and increased production of enzyme to metabolize cannabinoids. In contrast, TLE inhibited CYP2D6 gene expression and reduced the production of enzyme that activates codeine to morphine intoxication; this effect is the result of the phase II enzymeinducing properties of TLE (Oonsivilai et al., 2007). These increases in phase II enzymes supported better detoxification and maintained a healthy balance between phase I and phase II xenobiotic biotransformation. Drug-metabolizing enzymes that were induced by TLE resulted in an accelerated metabolism and generation of increased inactive or non-toxic products. P-gp plays a significant role in drug absorption, distribution, and excretion, and in vivo P-gp activity against herbs or drugs can be extrapolated reasonably well from in vitro data (Lin, 2003). These interactions are a way to reduce the bioavailability of toxic agents that are CYP450 and P-gp substrates. In this study, phytochemicals of T. laurifolia could increase P-gp activity, which accelerated the excretion of toxic substances from the cells. The mechanism behind these reactions was believed to be the induction/repression of drug metabolizing enzymes, in particular CYP450, together with induced P-gp activity, to reduce the adverse effects of toxic agents through excretion.

TLE significantly induced the expression of CYP3A4 and PPAR $\gamma$ in HepG2 cells in a unique dose-dependent manner. The 200 and $400 \mathrm{mg} / \mathrm{L}$ TLE doses progressively increased CYP3A4 and PPAR $\gamma$ gene expression, respectively. This particular biological activity of TLE was similar to that of black sticky rice extract, which acted in a concentration-dependent fashion with a biphasic "up then down" effect on LDLR mRNA expression in HepG2 cells (Sangkitikomol et al., 2010). PPAR $\gamma$ plays essential roles in metabolic syndromes. Active PPAR $\gamma$ results in metabolic interactions of lipid and carbohydrate metabolism, leading to reduced glucose levels, and PPAR $\gamma$ plays a major role in adipocyte differentiation (Everett et al., 2000). The other report found that PPAR $\gamma$ may play an antitoxic role by inducing liver cells to deposit harmless lipids, and it prevents the accumulation of toxic lipid species (Medina-Gomez et al., 2007). Moreover, PPAR $\gamma$ has a protective role against hepatotoxicity and may induce differentiation and apoptosis of various human malignant cells as well (Shimada et al., 2002).

The administration of TLE resulted in reduced and/or excreted toxic agents. This study gave sufficient evidence to indicate that TLE inhibits CYP3A7, CYP2D6, and CYP2E1 and induces CYP1A1, CYP1A2, CYP2B6, PPAR $\gamma$, and P-gp function. Additionally, TLE induces CYP3A4 at low doses and inhibits it at high doses. According to these properties, TLE is effectively used in Thai traditional medicine for protection against a variety of food and environmental toxic agents. However, caution is advised when TLE is used as co-medication 
with drugs that are CYP450 and P-gp substrates. It may result in diminished clinical effectiveness and/or increased dosage requirements.

\section{CONCLUSION}

TLE possessed high antioxidant levels that could reduce oxidative stress in the cells in a dose-dependent manner. Optimum doses of TLE significantly enhanced the mRNA expression of CYP1A1, CYP1A2, CYP3A4, CYP2B6, and PPAR $\gamma$ but inhibited the mRNA expression of CYP2D6, CYP3A7, and CYP2E1. TLE may be beneficial for health protection by reducing oxidative stress and minimizing toxicity by regulating the mRNA expression of CYP450 for suitable production of CYP450 isoenzymes in HepG2 cells, thereby maintaining xenobiotic biotransformation balance. Moreover, TLE could increase P-gp activity, which accelerated the excretion of toxic substances from the cells. The mechanism behind these reactions was believed to be the regulation of phase I metabolizing enzymes, in particular CYP450, together with the multidrug transporter P-gp. Finally, TLE induced the expression of PPAR $\gamma$; this gene may regulate energy metabolism, anti-inflammatory responses, and reduce the risk of hepatotoxicity and carcinogenicity induced by toxic substances.

\section{ACKNOWLEDGMENTS}

Research supported by the Rachadaphisaksomphot Endowment Fund (Part of the Strengthen CU's Researcher Project) and the Chulalongkorn University Centenary Academic Development Project. The authors gratefully acknowledge the generous gift of the HepG2 cells from Assoc. Prof. Dr. Parvapan Bhattarakosol.

\section{REFERENCES}

Abass K, Turpeinen M and Pelkonen O (2009). An evaluation of the cytochrome P450 inhibition potential of selected pesticides in human hepatic microsomes. J. Environ. Sci. Health B 44: 553-563.

Bailey DG and Dresser GK (2004). Interactions between grapefruit juice and cardiovascular drugs. Am. J. Cardiovasc. Drugs 4: 281-297.

Butura A, Nilsson K, Morgan K, Morgan TR, et al. (2009). The impact of CYP2E1 on the development of alcoholic liver disease as studied in a transgenic mouse model. J. Hepatol. 50: 572-583.

Calkin AC and Tontonoz P (2010). Liver x receptor signaling pathways and atherosclerosis. Arterioscler. Thromb. Vasc. Biol. 30: 1513-1518.

Chen C, Yu R, Owuor ED and Kong AN (2000). Activation of antioxidant-response element (ARE), mitogen-activated protein kinases (MAPKs) and caspases by major green tea polyphenol components during cell survival and death. Arch. Pharm. Res. 23: 605-612.

Davalos A, Gomez-Cordoves C and Bartolome B (2004). Extending applicability of the oxygen radical absorbance capacity (ORAC-fluorescein) assay. J. Agric. Food Chem. 52: 48-54.

Everett L, Galli A and Crabb D (2000). The role of hepatic peroxisome proliferator-activated receptors (PPARs) in health and disease. Liver 20: 191-199.

Gasche Y, Daali Y, Fathi M, Chiappe A, et al. (2004). Codeine intoxication associated with ultrarapid CYP2D6 metabolism. N. Engl. J. Med. 351: 2827-2831.

Guengerich FP (2008). Cytochrome p450 and chemical toxicology. Chem. Res. Toxicol. 21: 70-83.

Hamidovic A, Hahn K and Kolesar J (2010). Clinical significance of ABCB1 genotyping in oncology. J. Oncol. Pharm. Pract. 16: 39-44.

Han FM, Yang QC, Du P and Wu WH (2009). The metabolism of strychnine in rat liver microsomes and metabolic interaction with glycyrrhetic acid in vitro. Asian J. Pharmacodyn. Pharmacokinet. 9: 301-312. 
Huang D, Ou B and Prior RL (2005). The chemistry behind antioxidant capacity assays. J. Agric. Food Chem. 53: 1841-1856. Jaiboon V, Boonyanuphap J, Suwansri S, Ratanatraiwong P, et al. (2011). Alpha amylase inhibition and roasting time of local vegetables and herbs prepared for diabetes risk reducing chili paste. As. J. Food Ag.-Ind. 4: 103-113.

Jia JX and Wasan KM (2008). Effects of monoglycerides on rhodamine 123 accumulation, estradiol 17 beta-D-glucuronide bidirectional transport and MRP2 protein expression within Caco-2 cells. J. Pharm. Pharm. Sci. 11: 45-62.

Kaul D, Shukla AR, Sikand K and Dhawan V (2005). Effect of herbal polyphenols on atherogenic transcriptome. Mol. Cell Biochem. 278: 177-184.

Kim SN, Seo JY, Jung dW, Lee MY, et al. (2007). Induction of hepatic CYP2E1 by a subtoxic dose of acetaminophen in rats: increase in dichloromethane metabolism and carboxyhemoglobin elevation. Drug Metab. Dispos. 35: 1754-1758.

Kong AN, Yu R, Chen C, Mandlekar S, et al. (2000). Signal transduction events elicited by natural products: role of MAPK and caspase pathways in homeostatic response and induction of apoptosis. Arch. Pharm. Res. 23: 1-16.

Kumagai Y and Sumi D (2007). Arsenic: signal transduction, transcription factor, and biotransformation involved in cellular response and toxicity. Annu. Rev. Pharmacol. Toxicol. 47: 243-262.

Lander HM (1997). An essential role for free radicals and derived species in signal transduction. FASEB J. 11: 118-124.

Lin JH (2003). Drug-drug interaction mediated by inhibition and induction of P-glycoprotein. Adv. Drug Deliv. Rev. 55: 53-81.

Madabushi R, Frank B, Drewelow B, Derendorf H, et al. (2006). Hyperforin in St. John's wort drug interactions. Eur. J. Clin. Pharmacol. 62: 225-233.

Medina-Gomez G, Gray SL, Yetukuri L, Shimomura K, et al. (2007). PPAR gamma 2 prevents lipotoxicity by controlling adipose tissue expandability and peripheral lipid metabolism. PLoS Genet. 3: e64.

Oonsivilai R, Cheng C, Bomser J, Ferruzzi MG, et al. (2007). Phytochemical profiling and phase II enzyme-inducing properties of Thunbergia laurifolia Lindl. (RC) extracts. J. Ethnopharmacol. 114: 300-306.

Powell EE and Kroon PA (1994). Low density lipoprotein receptor and 3-hydroxy-3-methylglutaryl coenzyme A reductase gene expression in human mononuclear leukocytes is regulated coordinately and parallels gene expression in human liver. J. Clin. Invest. 93: 2168-2174.

Pramyothin P, Chirdchupunsare H, Rungsipipat A and Chaichantipyuth C (2005). Hepatoprotective activity of Thunbergia laurifolia Linn extract in rats treated with ethanol: in vitro and in vivo studies. J. Ethnopharmacol. 102: 408-411.

Sangkitikomol W, Tencomnao T and Rocejanasaroj A (2010). Effects of Thai black sticky rice extract on oxidative stress and lipid metabolism gene expression in HepG2 cells. Genet. Mol. Res. 9: 2086-2095.

Sen S, Chakraborty R, Sridhar C and Reddy YSR (2010). Free radicals, antioxidants, diseases and phytomedicines: Current status and future prospect. IJPSR 3: 91-100.

Shimada T, Kojima K, Yoshiura K, Hiraishi H, et al. (2002). Characteristics of the peroxisome proliferator activated receptor gamma (PPARgamma) ligand induced apoptosis in colon cancer cells. Gut 50: 658-664.

Singleton VL, Orthofer R and Lamuela-Raventos RM (1999). Analysis of total phenols and other oxidation substrates and antioxidants by means of Folin-Ciocalteu reagent. Meth. Enzymol. 299: 152-178.

Takahashi S, Takahashi T, Mizobuchi S, Matsumi M, et al. (2002). Increased cytotoxicity of carbon tetrachloride in a human hepatoma cell line overexpressing cytochrome P450 2E1. J. Int. Med. Res. 30: 400-405.

Tejasen P and Thongthapp C (1980). The study of the insecticide antitoxicity of Thunbergia laurifolia Linn. Chiang Mai Med. Bull. 19: 105-114.

Twentyman PR and Luscombe M (1987). A study of some variables in a tetrazolium dye (MTT) based assay for cell growth and chemosensitivity. Br. J. Cancer 56: 279-285.

Wang H and Joseph JA (1999). Quantifying cellular oxidative stress by dichlorofluorescein assay using microplate reader. Free Radic. Biol. Med. 27: 612-616.

Watanabe K, Yamaori S, Funahashi T, Kimura T, et al. (2007). Cytochrome P450 enzymes involved in the metabolism of tetrahydrocannabinols and cannabinol by human hepatic microsomes. Life Sci. 80: 1415-1419.

Wenk M, Todesco L and Krahenbuhl S (2004). Effect of St John's wort on the activities of CYP1A2, CYP3A4, CYP2D6, $\mathrm{N}$-acetyltransferase 2, and xanthine oxidase in healthy males and females. Br. J. Clin. Pharmacol. 57: 495-499.

Williams RJ, Spencer JP and Rice-Evans C (2004). Flavonoids: antioxidants or signalling molecules? Free Radic. Biol. Med. 36: 838-849.

Willson TM, Lambert MH and Kliewer SA (2001). Peroxisome proliferator-activated receptor gamma and metabolic disease. Аnпи. Rev. Biochem. 70: 341-367.

Wonkchalee O, Boonmars T, Aromdee C, Laummaunwai P, et al. (2012). Anti-inflammatory, antioxidant and hepatoprotective effects of Thunbergia laurifolia Linn. on experimental opisthorchiasis. Parasitol. Res. 111: 353-359.

Woodcroft KJ, Hafner MS and Novak RF (2002). Insulin signaling in the transcriptional and posttranscriptional regulation of CYP2E1 expression. Hepatology 35: 263-273.

Zhang SZ, Lipsky MM, Trump BF and Hsu IC (1990). Neutral red (NR) assay for cell viability and xenobiotic-induced cytotoxicity in primary cultures of human and rat hepatocytes. Cell Biol. Toxicol. 6: 219-234. 